\title{
Development of precision methods for remote monitoring of weeds
}

\author{
Roman Danilov ${ }^{*}$, Roman Zelensky, Artyom Ponomarev, Mariya Ivanisova, and Kseniya \\ Gasiyan
}

All-Russian Research Institute of Biological Plant Protection, Krasnodar-39, 350039, Russia

\begin{abstract}
As a result of hyperspectral measurements carried out on the test plots of the All-Russian Research Institute of Biological Plant Protection, we obtained the reflection spectra of individual cultivated and weed species. Along with the ground-based measurements, trials of the GEOSCAN drone equipped with a Gamaya hyperspectral camera were organized. We developed a database of spectral characteristics of weeds. The change in the shape of the spectral signatures of the reflectivity of plant objects depending on their actual condition, taken into account during field surveys, was analyzed. An analysis of the spectral curves showed that the results of field spectrometry are in good agreement with aerial survey data.
\end{abstract}

\section{Introduction}

Weed plants are components of secondary habitats plant communities and essentially remain wild-growing plants, the distribution of which is caused, first of all, by natural factors, the main of which is the heat and moisture supply of the growing area, rather than being attached to a specific agricultural crop $[1,2]$.

To carry out real-time monitoring of agrocenoses conditions, it is necessary to improve methods for obtaining information on weeds in specific regions with reference to agroclimatic conditions [3,4]. That's why it's really important to develop fundamentally new diagnostic tools and operational control of especially dangerous harmful species that can cause an emergency food situation [5-7].

Currently, in many countries of the world drones (UAVs) are used to control agricultural land, in economic terms the cost of their application is many times cheaper than using aviation and space systems [8-10]. The Russian experience in the use of UAVs in agriculture today mainly comes down to determining the area of agricultural land, the general economic assessment of crops conditions and the determination of the NDVI index (Normalized Difference Vegetation Index) [11-13]. At the same time, there is a lack of proposals for the use of modern technical tools for diagnosing the species composition and prognostic models of development, and the spread of harmful objects.

'Corresponding author: daniloff.roman2011@yandex.ru 
Modern specialized literature contains some articles considering the problems of the development of ground-based spectral libraries, providing the possibility of identifying species features and changing the condition of different types of vegetation caused by the influence of environmental factors $[14,15]$.

The aim of our research was to improve phytosanitary monitoring methods for weeds.

\section{Materials and methods}

To achieve this goal, on the experimental fields of scientific crop rotation of the AllRussian Research Institute of Biological Plant Protection, we developed test plots with different species composition of cultivated and weed plants that form the basis of the agrocenoses of Krasnodar Krai [16].

The objects of the research were crops of sunflower, corn, soybeans and alfalfa, to different extents weeded with the following species: ragweed (Ambrosia artemisiifolia L.), Californian burweed (Xanthium strumarium L.), black foxtail (Alopecurus myosuroides Huds.) and wild oat (Avena fatua L.).

In the course of the research, we carried out regular phytosanitary monitoring of the development of cultivated and weed plants during the study period.

Ground-based spectrometric measurements were carried out using a FieldSpec 3 Hi-Res spectroradiometer, which is designed to measure the absolute and relative values of energy brightness in the spectral range of $350 \div 2500 \mathrm{~nm}$.

Along with the ground-based measurements, we tested GEOSCANAGRO-101 drone equipped with an OXIVNIR-40 hyperspectral camera.

\section{Results and discussion}

As a result of hyperspectral measurements carried out on the test plots, we obtained reflection spectra for certain types of cultivated plants (corn, sunflower, soybeans) and weeds (ragweed, Californian burweed, field sow thistle, foxtail, etc.).

Basing on the data processing, we developed a database of spectral characteristics of crops and weeds in the Microsoft Acces 2010 program.

We analyzed the change in the shape of the spectral signatures of the reflectivity of plant objects depending on their actual condition, taken into account during field surveys. Figure 1 shows the average graphs of the dependence of spectral brightness on the wavelength of cultivated and weed plants in the third decade of May. This time period is the beginning of the active vegetation of weeds.

An analysis of the spectral curves showed that the data from ground-based field spectrometry are in good agreement with the aerial survey data. Corn and soybean plants are characterized by similar reflectivity in the visible range of 450-680 nm. Sunflower is characterized by the most significant steepness of the green reflection peak. Alfalfa reflection curve significantly coincides with the spectral brightness indices of the Californian burweed (X. strumarium L.), only slightly differing in the green reflection peak Wild oats (A. fatua L.) differs from other plants in the most profound absorption of radiation in the red part of the spectrum. Ragweed (A. artemisiifolia L.) is characterized by an extremely low, in comparison with other plants index of spectral brightness in the visible range, as well as an upper limit of reflection in the infrared region of electromagnetic radiation. 


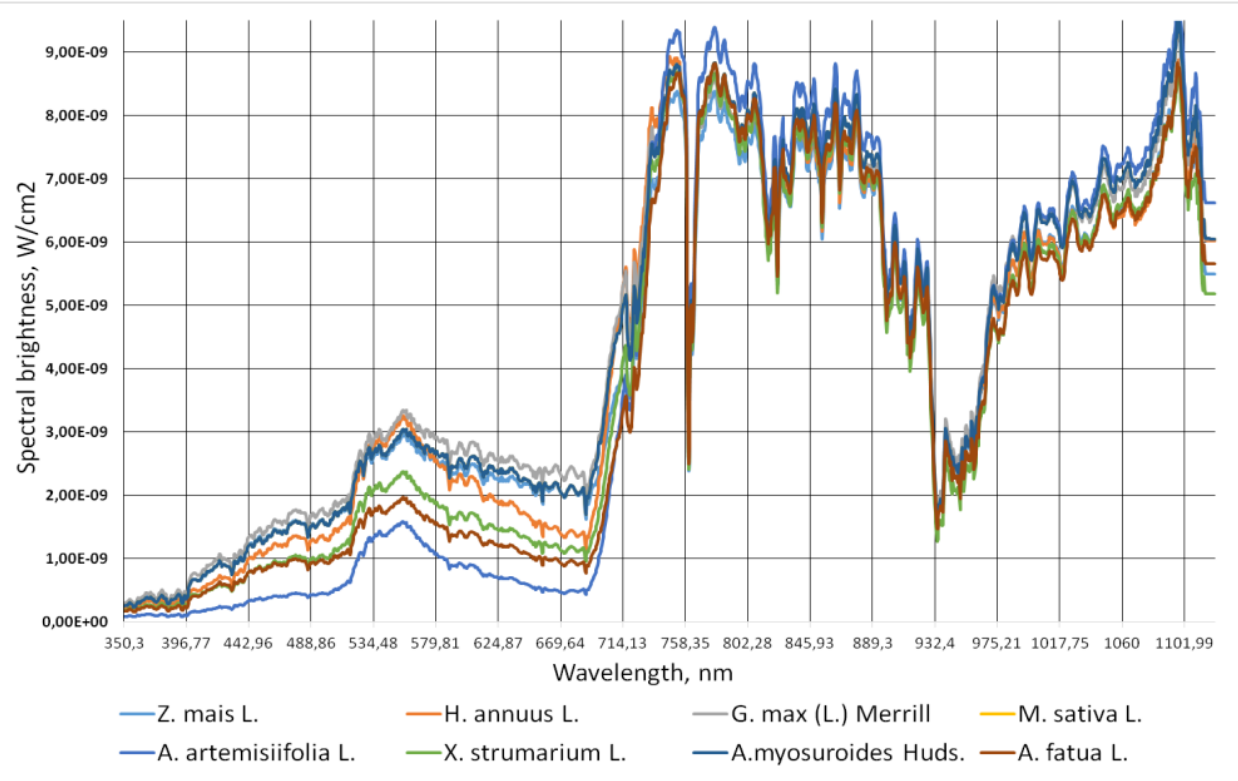

Fig. 1. Average graphs of the dependence of spectral brightness on the wavelength of cultivated and weed plants in the third decade of May

Table 1 shows the results of a statistical calculation of the ranges of spectral brightness values of cultivated and weed plants.

Table 1. Assessment of the spectral characteristics of cultivated and weed plants in the third decade of May

\begin{tabular}{|c|c|c|c|c|c|}
\hline \multirow{2}{*}{ Plant species } & \multicolumn{5}{|c|}{ Reflectivity, \% } \\
\hline & B & $\mathrm{G}$ & $\mathrm{R}$ & $\mathrm{RE}$ & NIR \\
\hline Z. mais L. & $1,42 \pm 0,17$ & $2,42 \pm 0,18$ & $1,97 \pm 0,23$ & $3,76 \pm 0,35$ & $5,43 \pm 0,47$ \\
\hline H. annuus L. & $1,21 \pm 0,07$ & $2,19 \pm 0,14$ & $1,43 \pm 0,07$ & $4,42 \pm 0,25$ & $5,47 \pm 0,27$ \\
\hline G. $\max ($ L.) Merrill & $1,51 \pm 0,08$ & $2,63 \pm 0,07$ & $2,21 \pm 0,14$ & $4,36 \pm 0,15$ & $5,49 \pm 0,23$ \\
\hline M. sativa L. & $0,85 \pm 0,05$ & $1,71 \pm 0,12$ & $1,28 \pm 0,12$ & $3,71 \pm 0,18$ & $5,58 \pm 0,11$ \\
\hline A. artemisiifolia $L$. & $0,42 \pm 0,03$ & $1,07 \pm 0,05$ & $0,47 \pm 0,03$ & $3,23 \pm 0,12$ & $5,65 \pm 0,18$ \\
\hline X. strumarium L. & $1,03 \pm 0,23$ & $2,01 \pm 0,53$ & $1,27 \pm 0,25$ & $3,91 \pm 0,72$ & $5,17 \pm 0,23$ \\
\hline A. myosuroides Huds. & $1,31 \pm 0,12$ & $2,26 \pm 0,18$ & $1,83 \pm 0,26$ & $4,12 \pm 0,21$ & $5,61 \pm 0,23$ \\
\hline A. fatua $\mathrm{L}$ & $0,81 \pm 0,05$ & $1,41 \pm 0,09$ & $0,91 \pm 0,08$ & $2,93 \pm 0,19$ & $5,07 \pm 0,33$ \\
\hline
\end{tabular}

In general, the statistical calculation data confirmed the results of a graphical analysis of the comparison of the spectral signatures of the studied plant objects and allowed us to draw the following conclusions:

- distinctive features of the reflectivity of some cultivated and weed species are in the visible range of the spectrum of $400 \div 680 \mathrm{~nm}$;

- $\quad$ in the NIR range of $800 \div 1100 \mathrm{~nm}$, the differences in the average values of the spectral brightness of different plant species are overlapped by the sums of their standard deviations;

- $\quad$ ragweed is characterized by a pronounced difference in the amplitude of spectral brightness fluctuations from the total set of reflection spectra of cultivated and weed plants. 


\section{Conclusions}

Thus, as a result of the studies, we obtained the original spectral characteristics of certain species of cultivated and weed plants. We interpreted and compared the data obtained as a result of ground-based and remote measurements, and indicative spectral characteristics of individual plant species were revealed. We developed a database of hyperspectral optical characteristics of crops and weeds.

The obtained results indicate the fundamental possibility of using remote hyperspectral measurements for phytosanitary monitoring of weeds.

The research was supported by the RFBR grant and the Administration of Krasnodar Krai No 19-416-233025 р_мол_а

\section{References}

1. N. Luneva, Yu. Fedorova, Agro-industrial technologies of Central Russia J. 1(15) (2020) http://elsu.ru/agrotech/issues/229/articles/3012/

2. N. Luneva, Yu. Fedorova, Plant Protection News J. 2(100), 15-23 (2020) http://doi.org/ 10.31993/2308-6459-2019-2(100)-15-23

3. A.N. Afonin, Luneva N.N., Yu.S. Li, N.V. Kotsareva, Russian Journal of Ecology J. 48(1), 86-89 (2017) https://www.libnauka.ru/item.php?doi=10.7868/S0367059717010036

4. A.N.a, Afonin Y.A.a Fedorova, Yu.S. Li, Russian Journal of Biological Invasions J. 3(10), 220-226 (2019) https://link.springer.com/article/10.1134/S2075111719030032

5. O.Ye. Arkhipova, N.A. Kachalina, Yu.V. Tyutyunov, O.V. Kovalev, Issledovaniya Zemli iz kosmosa. $\quad \mathbf{6}, \quad 15-26 \quad$ (2014) https://elibrary.ru/item.asp?doi=10.7868/S0205961414050017

6. R. Ngom, P. Gosselin, Select. Top. Appl. Earth Obs. Rem. Sens. J. 7(1), 19391404 (2013) http://doi.org/ 10.1109/JSTARS.2013.2254469

7. R.Yu. Danilov, V.Ya. Ismailov, V.A. Tretyakov, O.Yu. Kremneva, Yu.V. Shumilov, A.A. Rizvanov, V.V. Krivoshein, I.A. Kostenko, Achievements of Science and Technology of AICis. 32(10), 82-86 (2018) http://agroapk.ru/2018-g/138-archive/102018/2800-2018-10-19-ru

8. A.V. Shevchenko, A.N. Migachev, Robotics and Technical Cybernetics J. 7(3), 183-195 (2019) http://doi.org/ 10.31776/RTCJ.7303

9. G.A.Yu. Astapov, K.A. Prishutov, I.P. Krivolapov, S.Y. Astapov, A.A. Korotkov, Amazonia Investiga J. 8(23), 27-36 (2019)

https://www.amazoniainvestiga.info/index.php/amazonia/article/view/839

10. I.M. Sutugina, R.G. Mamin, Vestnik Orel GAU J. 3(42), 2-6 (2013) https://doi.org/10.3846/16487788.2013.861224

11. I.Yu. Savin1, Yu.I. Vernyuk1, G. Faraslis, Bulletin of the Dokuchaev Soil Institute J. 80, 95-105 (2015) https://doi.org/10.19047/0136-1694-2015-80-95-105

12. Yu.N. Zubarev, D.S. Fomin1, A.N. Chashchin, M.V. Zabolotnova, Bulletin of the Perm Federal research center J. 2, 47-51 (2019) https://doi.org/10.7242/2658705X/2019.2.5

13. V. Starovoitov, O. Starovoitova, V. Balabanov, A. Manokhina, Science in central Russia J. 6(42), 91-99 (2019) http://doi.org/ 10.35887/2305-2538-2019-6-91-99

14. A.N. Grigor'yev, D.M. Ryzhikov. Current problems in remote sensing of the earth from space. 15(1), 183-192 (2018) http://doi.org/ 10.21046/2070-7401-2018-15-1-183-192

15. R.Yu. Danilov, O.Yu. Kremneva, V.Ya. Ismailov, V.A. Tretyakov, A.A. Rizvanov, V.V. Krivoshein, A.A. Pachkin, Current problems in remote sensing of the earth from space. 17(1), 113-127 (2020) https://doi.org/ 10.21046/2070-7401-2020-17-1$\underline{113-127}$ 
16. N.N. Luneva, T.Y. Zakota, Plant Protection News J. 1(95), 45-52 (2018) http://doi.org/ 10.31993/2308-6459-2018-1(95)-45-52 